\title{
Synthesis and Properties of Optically Active Polyester-amides from Ester-Containing Chiral Dicarboxylic Acid and Aromatic Diamines
}

\author{
Tohru Kobayashi, Masa-aki KaKimoto,* and Yoshio ImaI*, ${ }^{\dagger}$ \\ Takasago International Corporation, Kamata, Ohta-ku, Tokyo 144, Japan \\ * Department of Organic and Polymeric Materials, Tokyo Institute of Technology, \\ Meguro-ku, Tokyo 152, Japan
}

(Received July 20, 1992)

\begin{abstract}
The asymmetric hydrogenation of benzyl acetoacetate afforded benzyl $(R)-3$ hydroxybutanoate (II). Optically active ester-containing dicarboxylic acid $\mathbf{V}$ was newly prepared from II and terephthaloyl chloride, followed by debenzylation. The polycondensation of $\mathbf{V}$ with aromatic diamines was carried out in the presence of triphenyl phosphite, pyridine, and calcium chloride in $N$-methyl-2-pyrrolidone (NMP). The resulting optically active polyester-amides had inherent viscosities of $0.44-0.79 \mathrm{dl} \mathrm{g}^{-1}$, and specific rotations from $-43.6^{\circ}$ to $-78.5^{\circ}$. The glass transition temperatures of the polymers were in the range from $129^{\circ} \mathrm{C}$ to $169^{\circ} \mathrm{C}$, and their decomposition started at a temperature from $231^{\circ} \mathrm{C}$ to $249^{\circ} \mathrm{C}$ to afford biscrotonamide and terephthalic acid. The glass transition temperature of the optically active polymer derived from $4,4^{\prime}$-oxydianiline was $8^{\circ} \mathrm{C}$ higher than that of the corresponding inactive analogue.

KEY WORDS Optically Active Polyester-amides / Asymmetric Hydrogenation / Polycondensation / Thermal Behavior /
\end{abstract}

Several examples of optically active polymers obtained by polycondensation have been reported to investigate conformational behavior of the polymers in solution and physical properties such as melting point, glass transition temperature, crystallinity, solubility, and mechanical strength. ${ }^{1}$ Recently much interest has been focused on the synthesis of main chain liquid crystalline polymers containing optically active units. ${ }^{2}$ However, general sources of optically active monomers for the polycondensation are derivatives of naturally occurring compounds. Preparation of optically active monomers by asymmetric synthesis is of interest, because a variety of new types of optically pure intermediates could be obtained in both antipodes.

In this paper, we describe the preparation and characterization of optically active polyester-amides derived from some aromatic diamines and an optically active ester-containing dicarboxylic acid whose chiral centers are produced by the Ruthenium-Binap catalyzed asymmetric hydrogenation (Binap $=2,2^{\prime}$-bis(diphenylphosphino)-1,1'-binaphthyl).

\section{RESULTS AND DISCUSSION}

\section{Synthesis of Optically Active Diacid $\mathbf{V}$}

Optically active ester-containing dicarboxylic acid $\mathbf{V}$ was synthesized as shown in eq 1 .

The Ruthenium-Binap catalyzed asymmetric hydrogenation ${ }^{3}$ of benzyl acetoacetate (I) gave benzyl $(R)$-3-hydroxybutanoate (II) with $94.3 \%$ enantiomeric excess in $75 \%$ yield. Dibenzyl ester IV was prepared by the condensation of II with 0.5 molar equivalent of terephthaloyl chloride (III) in the presence

\footnotetext{
$\dagger$ To whom correspondence should be addressed.
} 


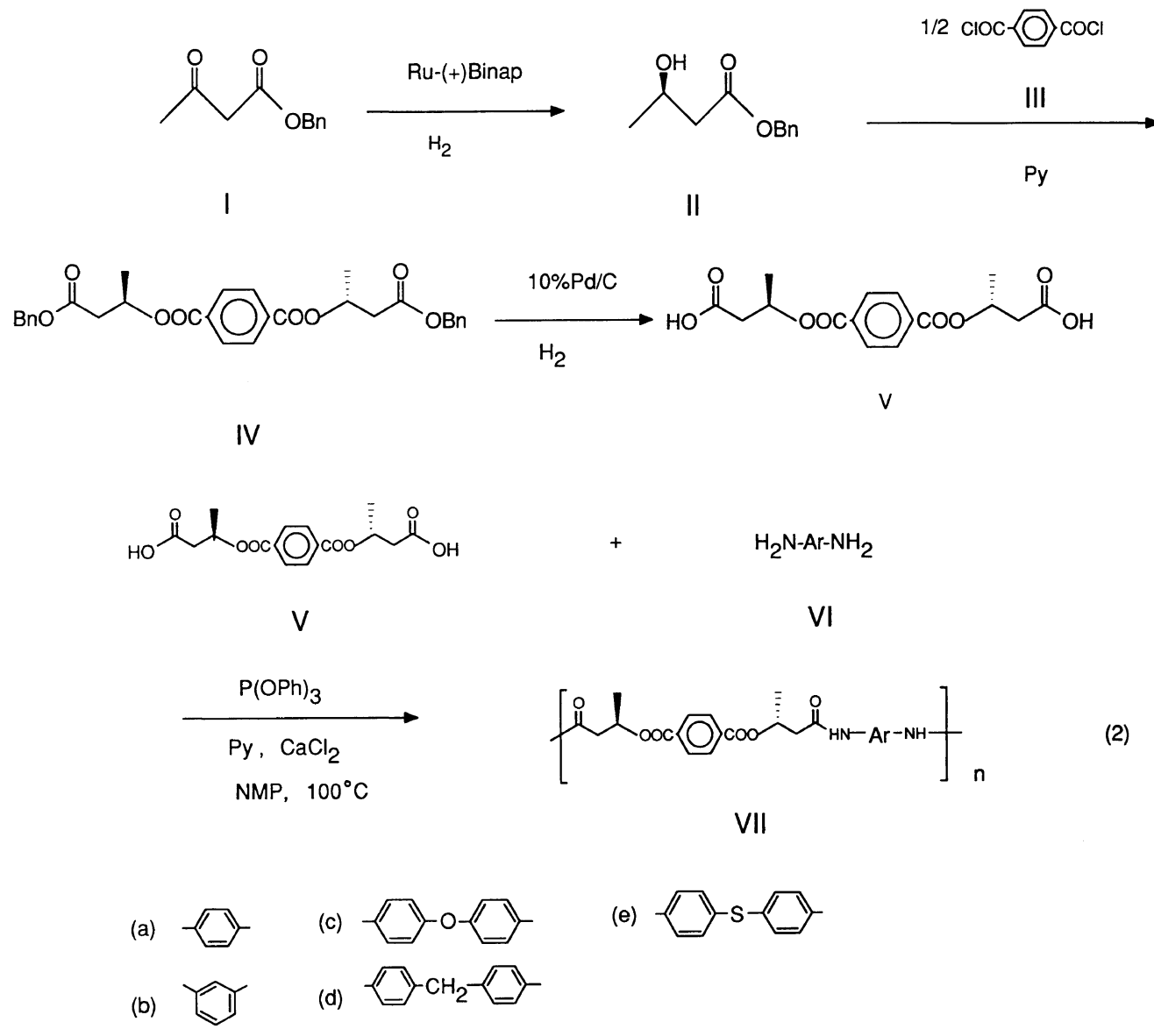

of pyridine in $79 \%$ yield. The removal of benzyl groups of IV by $\mathrm{Pd}-\mathrm{C}$ catalyzed hydrogenolysis produced crystals of optically active ester-containing dicarboxylic acid $\mathbf{V}$ in $65 \%$ yield. By using the same procedure, the corresponding optically inactive dicarboxylic acid VIII was also prepared from racemic benzyl 3-hydroxybutanoate which was obtained by the sodium borohydride reduction of benzyl acetoacetate (I). Dicarboxylic acid VIII had higher melting point and showed less solubility in organic solvents than optically active dicarboxylic acid $\mathbf{V}$.

\section{Synthesis of Polyester-amides}

Optically active dicarboxylic acid $\mathbf{V}$ was subjected to polycondensation with aromatic diamines VI such as $p$-phenylenediamine (VIa), m-phenylenediamine (VIb), 4,4'-oxydianiline (VIc), 4,4'-methylenedianiline (VId), and 4,4'thiodianiline (VIe) by using a direct polycondensation method in the presence of triphenyl phosphite, pyridine, and calcium chloride in $N$-methyl-2-pyrrolidone (NMP) at $100^{\circ} \mathrm{C}$ (eq 2).

Dicarboxylic acid VIII was further polycondensed with 4,4'-oxydianiline (VIc) to give optically inactive polyester-amide IX for comparison (eq 3).

The results of the polymerization are summarized in Table I. The yields and inherent viscosities of all the polymers were 85$95 \%$, and higher than $0.44 \mathrm{dl} \mathrm{g}^{-1}$, respectively. The gel permeation chromatography (GPC) indicated that the number-average molecular weight $\left(\bar{M}_{n}\right)$ values were $29000-86000$ based 
Optically Active Polyester-amides<smiles>C[C@@H](CO)CC(=O)Oc1ccc(OC(=O)C[C@@H](C)O[C@H](C)CC(=O)O)cc1</smiles>

VIII

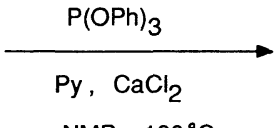

NMP, $100^{\circ} \mathrm{C}$

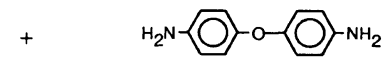

VIC

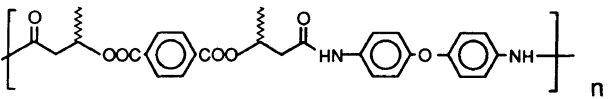

IX

Table I. Synthesis of optically active and inactive polyester-amides

\begin{tabular}{|c|c|c|c|c|c|c|c|}
\hline \multicolumn{2}{|c|}{ Monomers } & \multicolumn{6}{|c|}{ Polymer } \\
\hline \multirow{2}{*}{$\begin{array}{l}\text { Dicarboxylic } \\
\text { acid }\end{array}$} & \multirow{2}{*}{ Diamine } & \multirow{2}{*}{ Code } & \multirow{2}{*}{$\begin{array}{c}\text { Yield } \\
\%\end{array}$} & \multirow{2}{*}{$\frac{\eta_{\mathrm{inh}}^{\mathrm{a}}}{\mathrm{dl} \mathrm{g}^{-1}}$} & \multirow{2}{*}{$\begin{array}{c}\bar{M}_{n}^{\mathrm{b}} \\
\left(\times 10^{-4}\right)\end{array}$} & \multirow{2}{*}{$\begin{array}{c}\bar{M}_{w}{ }^{\mathrm{b}} \\
\left(\times 10^{-4}\right)\end{array}$} & \multirow{2}{*}{$\bar{M}_{w} / \bar{M}_{n}^{\mathrm{b}}$} \\
\hline & & & & & & & \\
\hline $\mathbf{V}$ & VIa & VIIa & 94 & 0.71 & 7.2 & 10.6 & 1.5 \\
\hline $\mathbf{V}$ & VIb & VIIb & 84 & 0.79 & 8.6 & 13.5 & 1.6 \\
\hline $\mathbf{V}$ & VIc & VIIc & 85 & 0.44 & 2.9 & 4.1 & 1.4 \\
\hline $\mathbf{V}$ & VId & VIId & 85 & 0.59 & 4.9 & 7.9 & 1.6 \\
\hline $\mathbf{V}$ & VIe & VIIe & 86 & 0.72 & 6.7 & 10.4 & 1.5 \\
\hline VIII & VIc & IX & 90 & 0.46 & 3.3 & 5.0 & 1.5 \\
\hline
\end{tabular}

a Measured at a concentration of $0.5 \mathrm{~g} \mathrm{dl}^{-1}$ in DMAc at $30^{\circ} \mathrm{C}$.

b Determined by GPC on the basis of polyoxyethylene calibration.

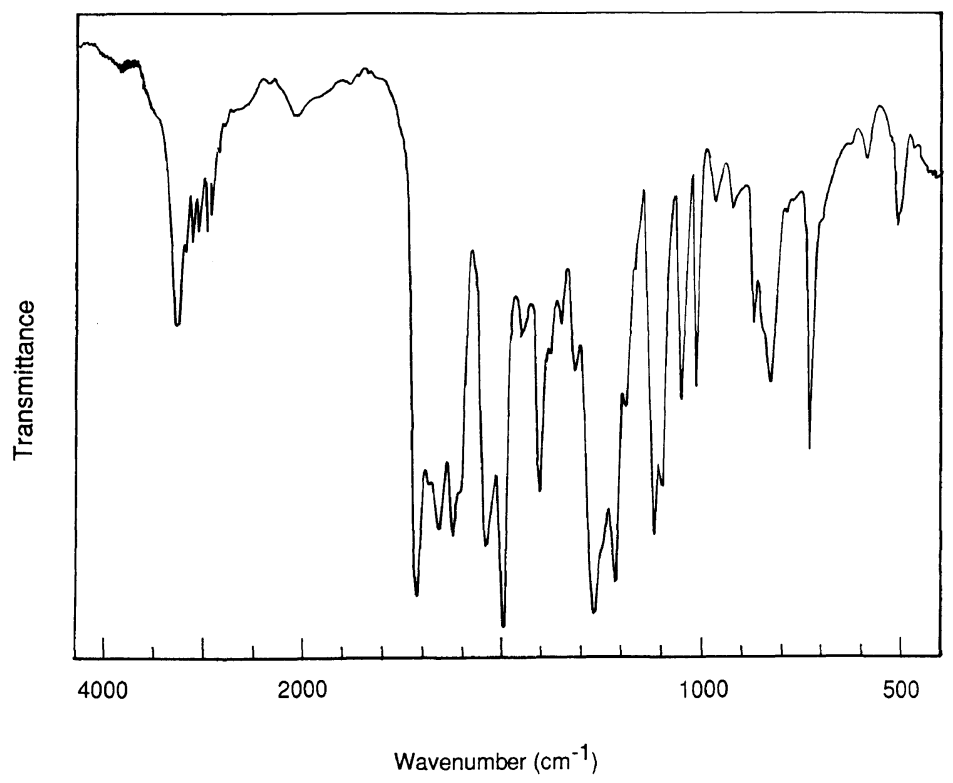

Figure 1. FT-IR spectrum of polymer VIIc (film). 


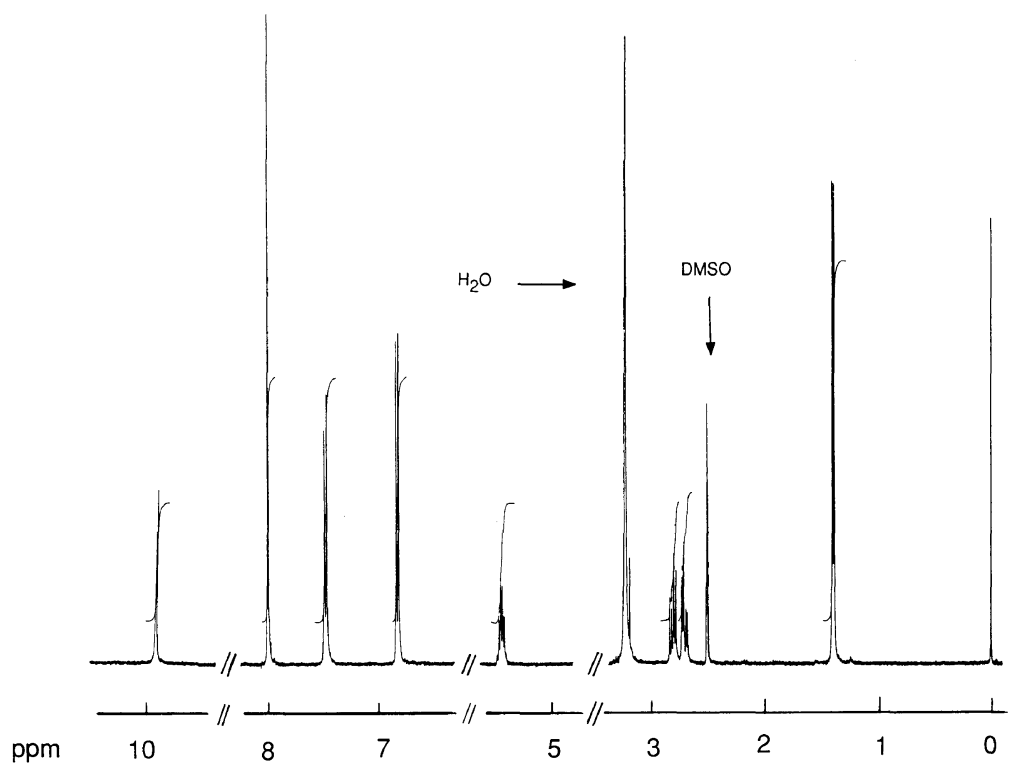

Figure 2. ${ }^{1} \mathrm{H}$ NMR spectrum measured in $\mathrm{CDCl}_{3}$ of polymer VIIc.

on standard polyoxyethylene, and the $\bar{M}_{w} / \bar{M}_{n}$ values were $1.4-1.6\left(\bar{M}_{w}\right.$, weight-average molecular weight).

All the polymers gave satisfactory results for the elemental analyses. The IR and ${ }^{1} \mathrm{H}$ NMR spectra of polymer VIIc are shown in Figures 1 and 2, respectively. The FT-IR spectra of the polymers exhibited characteristic absorptions of amide group at around $3300 \mathrm{~cm}^{-1}$ and $1661-1671 \mathrm{~cm}^{-1}$, and that of ester group at about $1720 \mathrm{~cm}^{-1}$. In the ${ }^{1} \mathrm{H}$ NMR spectra, the methyl protons gave doublet at about $1.4 \mathrm{ppm}$, and the nonequivalent geminal protons of methylene group next to the chiral center gave double-doublet at about $2.7 \mathrm{ppm}$ and $2.8 \mathrm{ppm}$. The methyne proton gave sextet at about $5.5 \mathrm{ppm}$ and the amide proton appeared at about $10 \mathrm{ppm}$.

\section{Properties of Polymers}

The X-ray diffraction studies revealed that all the polymers were amorphous. All the polymers were soluble in pyridine, dimethyl sulfoxide and amide solvents such as $N, N$ dimethylformamide (DMF), $N, N$-dimethylacetamide (DMAc), and NMP. No difference
Table II. Optical rotation values of polyester-amides $^{\mathbf{a}}$

\begin{tabular}{cccccc}
\hline & VIa & VIb & VIc & VId & VIe \\
\hline $\begin{array}{c}{[\alpha]_{\mathrm{D}}} \\
(\text { degree })\end{array}$ & -76.7 & -43.6 & -64.6 & -65.6 & -78.5 \\
\hline
\end{tabular}

a Measured in DMAc at a concentration of 0.64 $0.87 \mathrm{~g} \mathrm{dl}^{-1}$ at $25^{\circ} \mathrm{C}$.

in solubility in various solvents was observed between the optically active and inactive polymers. The polymers obtained from optically active dicarboxylic acid $\mathbf{V}$ had negative optical rotation values in the range from $-43.6^{\circ}$ to $-78.5^{\circ}$ as shown in Table II.

The thermal characterization of the polymers was carried out by means of dynamic mechanical analysis (DMA), differential thermal analysis (DTA), and thermogravimetry (TG). The glass transition temperatures $\left(T_{\mathrm{g}}\right)$ of the optically active polymers were observed in the range from $129^{\circ} \mathrm{C}$ to $169^{\circ} \mathrm{C}$ by the DMA measurments of the film samples. As shown in Figure 3, the optically active polymers exhibited a clear endotherm in the range of 
$233-249^{\circ} \mathrm{C}$. The TG measurements showed that all the polymers started to decompose at around $240^{\circ} \mathrm{C}$ and the $10 \%$ weight loss temperatures were in the range from 281 to $292^{\circ} \mathrm{C}$.

Figures 4 and 5 show the IR and ${ }^{1} \mathrm{H}$ NMR spectra, respectively, of thermally decomposed sample of VIIc at $240^{\circ} \mathrm{C}$ for $5 \mathrm{~min}$ under nitrogen. The absorption characteristic of ester carbonyl group disappeared and that of carboxylic acid was observed at $1680 \mathrm{~cm}^{-1}$ in the IR spectrum. In the ${ }^{1} \mathrm{H}$ NMR spectrum,

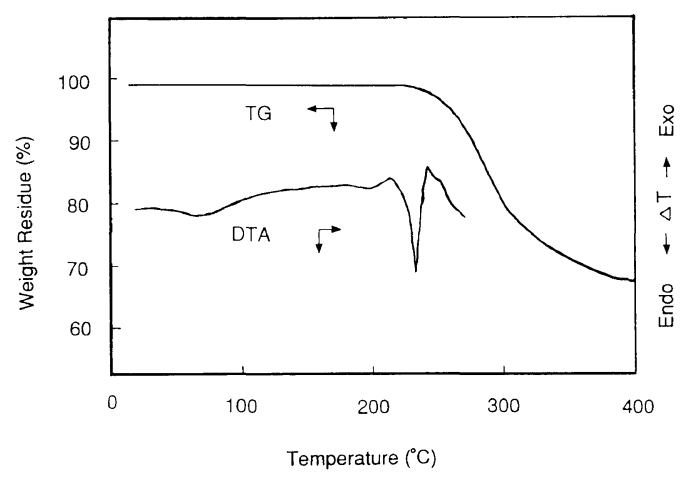

Figure 3. DTA and TG curves of VIIc at a heating rate of $10^{\circ} \mathrm{C} \mathrm{min}^{-1}$ in nitrogen. doublet of the methyl group migrated to $1.85 \mathrm{ppm}$ and double-doublet of the methylene group disappeared. Furthermore, characteristic peaks of the olefinic protons newly appeared in $6.10 \mathrm{ppm}$ and $6.78 \mathrm{ppm}$.

These spectroscopic data indicated that biscrotonamides $\mathbf{X}$ and terephthalic acid XI were produced by thermal main chain scission (eq 4) just after the endotherm observed by the DTA measurement. The same thermal behavior was reported in the copolyesters of poly(3-hydroxybutanoate), which degraded via six-membered ring transition state. ${ }^{4}$ The thermal behavior is surmmerized in Table III.

There has been several examples that optically active polymers have higher $T_{\mathrm{g}}$ than the corresponding racemic polymers because of stereoregularity of the polymer chain. ${ }^{5}$ In the present case, the difference in $T_{\mathrm{g}}$ between optically active polymer VIIc and its optically inactive analogue IX, both of which had almost the same inherent viscosities, was $8^{\circ} \mathrm{C}$. The little influence of stereoregularity of the optically active polymers on $T_{\mathrm{g}}$ could be explained by the fact that the concentration of asymmetric carbons in the polymer backbone

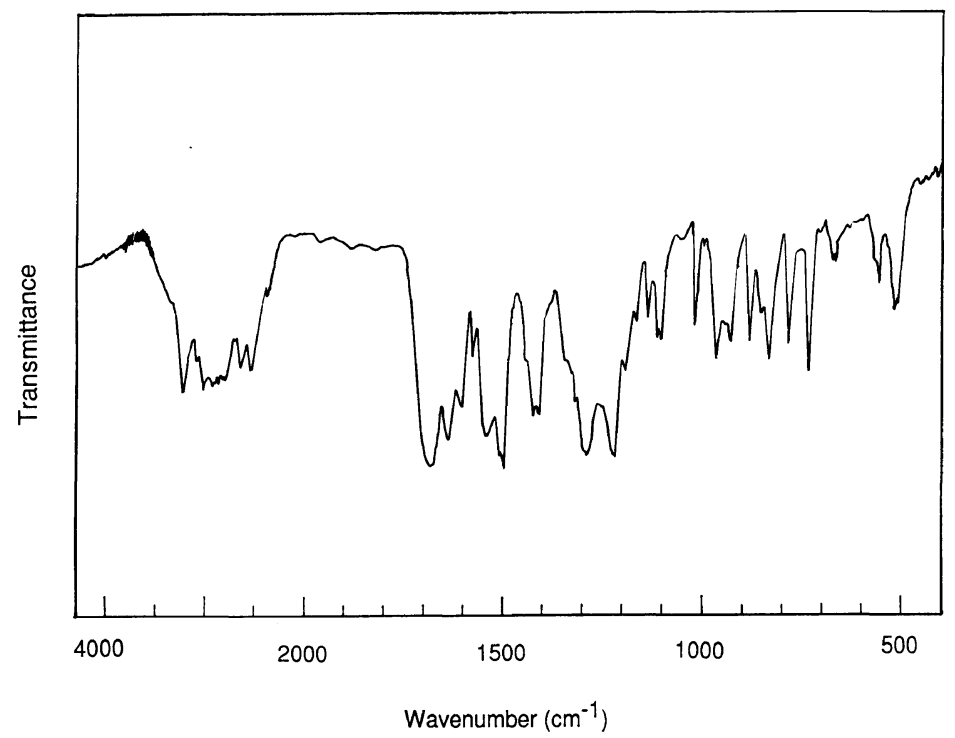

Figure 4. FT-IR spectrum of thermal decomposed sample of VIIc at $240^{\circ} \mathrm{C}$ for 5 min under nitrogen $(\mathrm{KBr})$. 


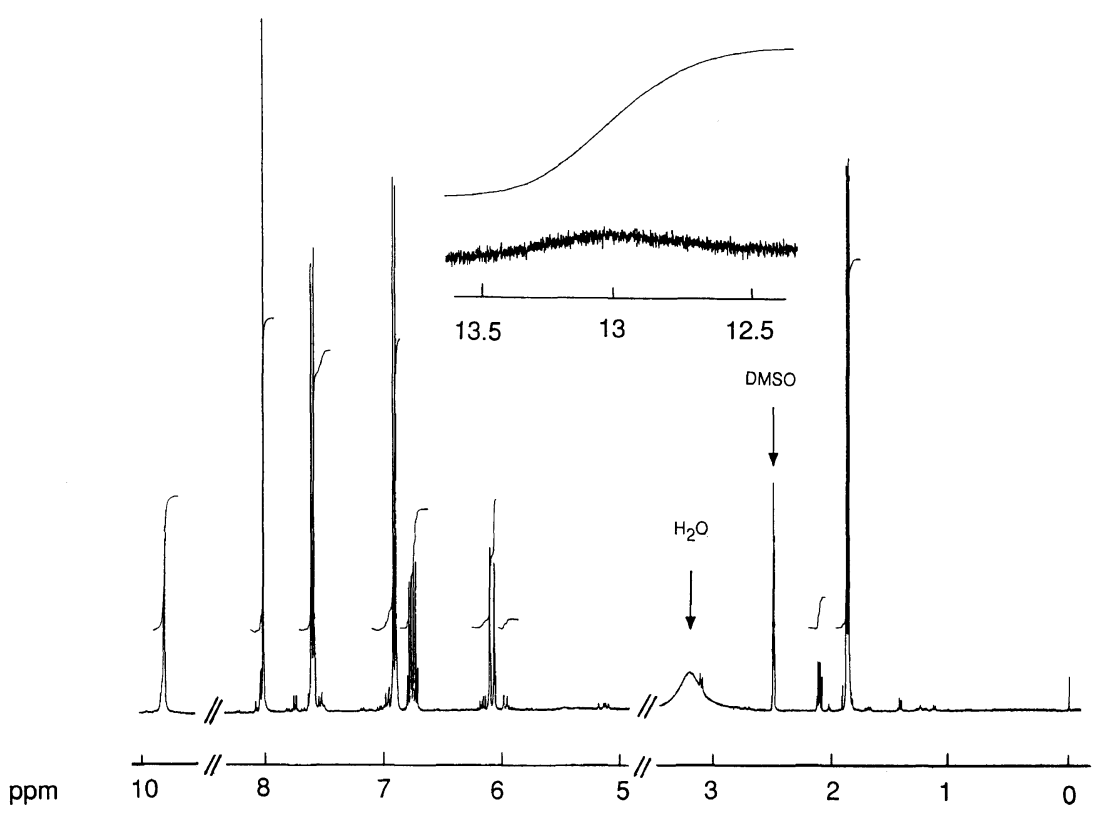

Figure 5. ${ }^{1} \mathrm{H}$ NMR sperctrum measured in $\mathrm{CDCl}_{3}$ of thermal decomposed sample of VIIc at $240^{\circ} \mathrm{C}$ for 5 min under nitrogen.

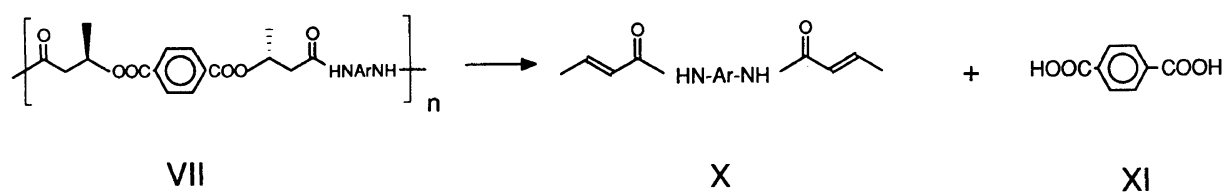

Table III. Thermal behavior of polyester-amides

\begin{tabular}{|c|c|c|c|}
\hline \multirow{2}{*}{ Polymer } & $T_{\mathbf{g}}^{\mathbf{a}}$ & $T_{\mathrm{d}}^{\mathbf{b}}$ & $T_{10}{ }^{\mathrm{c}}$ \\
\hline & ${ }^{\circ} \mathrm{C}$ & ${ }^{\circ} \mathrm{C}$ & ${ }^{\circ} \mathrm{C}$ \\
\hline VIIa & 160 & 249 & 274 \\
\hline VIIb & 138 & 241 & 284 \\
\hline VIIc & 129 & 233 & 283 \\
\hline IIId & 169 & 231 & 281 \\
\hline VIIe & 132 & 238 & 292 \\
\hline IX & 121 & 229 & 277 \\
\hline
\end{tabular}

a Determined by DMA at a heating rate of $3^{\circ} \mathrm{C} \mathrm{min}^{-1}$ at $10 \mathrm{~Hz}$.

b $T_{\mathrm{d}}$ is the decomposition temperature, determined by the peak top of the endotherm obtained by DTA in nitrogen at a heating rate of $10{ }^{\circ} \mathrm{Cmin}^{-1}$.

c $T_{10}$ is the temperature of $10 \%$ weight loss, measured by TG in nitrogen at a heating rate of $10^{\circ} \mathrm{C} \mathrm{min}^{-1}$. is relatively low.

\section{EXPERIMENTAL}

\section{Measurements}

IR spectra were recorded on a JASCO FT/IR-5000 spectrophotometer. ${ }^{1} \mathrm{H}$ NMR spectra were measured on a Bruker AMX 400 spectrometer $(400 \mathrm{MHz})$ using tetramethylsilane as an internal standard, and chemical shifts are quoted in ppm. Mass spectra were measured on both Hitachi M-80 and M-200 A spectrometers with relative intensities $(\%)$ in parentheses. Optical rotation measurements were obtained on a JASCO DIP-360 spectrometer. Dynamic mechanical analysis (DMA) was performed with a Toyoseiki RheolographSolid in tensile mode. Differential thermal 
analysis (DTA) and themogravimetry (TG) were performed with Shimazu thermal analyzers DTA-40 and TGA-40M, respectively, and measurements were run at a heating rate $10^{\circ} \mathrm{C} \mathrm{min}^{-1}$ under nitrogen at a flow rate of $50 \mathrm{ml} \mathrm{min}^{-1}$. Wide angle X-ray diffraction patterns were obtained at room temperature on a Rigakudenki RU-200 apparatus with nickel-filtered $\mathrm{Cu} K_{\alpha}$ radiation $(50 \mathrm{kV}, 180 \mathrm{~mA})$. Weight-average molecular weight $\left(\bar{M}_{w}\right)$ and number-average molecular weight $\left(\bar{M}_{n}\right)$ were determined by means of gel permeation chromatography (GPC) on the basis of polyoxyethylene calibration on a JASCO apparatus (eluent, DMF).

\section{Materials}

$m$-Phenylenediamine (VIb) and 4,4'-methylenedianiline (VId) were distilled under vacuum, and 4,4'-oxydianiline (VIc) was recrystallized from tetrahydrofuran. $p$-Phenylenediamine (VIa), 4,4'-thiodianiline (VIe), and calcium chloride were used as received. NMP, DMAc, and pyridine were purified by distillation over calcium hydride.

\section{Monomer Synthesis}

Synthesis of Benzyl (R)-3-hydroxybutanoate (II). A solution of benzyl acetoacetate (I) $(100 \mathrm{~g}, 0.52 \mathrm{~mol})$ and $\mathrm{Ru}_{2} \mathrm{Cl}_{4}\left((+) \mathrm{Binap}_{2} \mathrm{Et}_{3} \mathrm{~N}\right.$ $(1.25 \mathrm{~g})$ in methylene chloride $(400 \mathrm{ml})$ and water $(1 \mathrm{ml})$ was stirred at $40^{\circ} \mathrm{C}$ under hydrogen pressure of $80 \mathrm{~kg} \mathrm{~cm}^{-2}$. After stirring for $48 \mathrm{~h}$, the mixture was concentrated and the residue was distilled to give $78.3 \mathrm{~g}(77.6 \%)$ of benzyl $(R)$-3-hydroxybutanoate in $94.3 \%$ e.e. (determination of enantiomeric excess, see below).

bp $123-133^{\circ} \mathrm{C} / 1$ Torr, $[\alpha]_{\mathrm{D}}^{25}=-19.1^{\circ}(c=$ $5.0 \mathrm{~g} \mathrm{dl}^{-1}$ in $\left.\mathrm{CHCl}_{3}\right)$. (lit ${ }^{6}[\alpha]_{589}^{25}=-31.08^{\circ}$, $c=5.0 \mathrm{~g} \mathrm{dl}^{-1}$ in $\left.\mathrm{CHCl}_{3}\right)$.

IR (Neat): $3450(\mathrm{OH}), 2972,1730(\mathrm{C}=\mathrm{O})$, 1499, 1456, 1404, and $1293 \mathrm{~cm}^{-1}$.

${ }^{1} \mathrm{H} \mathrm{NMR}\left(\mathrm{CDCl}_{3}\right): 1.20(\mathrm{~d}, J=6.3 \mathrm{~Hz}, 3 \mathrm{H})$, $2.48(\mathrm{dd}, J=16.3 \mathrm{~Hz}, J=8.0 \mathrm{~Hz}, 1 \mathrm{H}), 2.50$ $(\mathrm{dd}, J=16.4 \mathrm{~Hz}, J=4.2 \mathrm{~Hz}, 1 \mathrm{H}), 2.80-2.95$ (br s, 1H), 4.15-4.28 (m, 1H), $5.15(\mathrm{~s}, 2 \mathrm{H})$, and $7.20-7.42(\mathrm{~m}, 5 \mathrm{H}) \mathrm{ppm}$.

Anal. Calcd for $\mathrm{C}_{11} \mathrm{H}_{14} \mathrm{O}_{3}: \mathrm{C}, 68.02 \% ; \mathrm{H}$, $7.26 \%$. Found: C, $68.43 \%$; H, $7.36 \%$.

\section{Determination of Optical Purity}

Enantiomeric excess (e.e.) of II was determinened by high performance liquid chromatography (column, Cosmosil 5SL, $4.6 \times 50 \mathrm{~mm}$, flow rate $1.0 \mathrm{ml} \mathrm{min}^{-1}$; eluent, $9: 1$ hexaneether; detection, $254 \mathrm{~nm}$ ) of its ( $R$ )-MTPA ester (MTPA $=\alpha$-methoxy- $\alpha$-trifluoromethylphenylacetyl). The retention times were $16.17 \mathrm{~min}$ ( $R$ isomer) and $18.68 \mathrm{~min}$ ( $S$ isomer) and the ratio of these peak areas is $34.2 / 1$ ( $94.3 \%$ e.e.).

Synthesis of Dibenzyl Ester IV. To a solution of benzyl $(R)$-3-hydroxybutanoate (II) $(50.0 \mathrm{~g}$, $0.257 \mathrm{~mol})$ and pyridine $(21.0 \mathrm{~g}, 0.266 \mathrm{~mol})$ in benzene $(300 \mathrm{ml})$ was added portionwise terephthaloyl chloride (III) $(21.0 \mathrm{~g}, 0.103 \mathrm{~mol})$ over $10 \mathrm{~min}$. The reaction mixture was stirred overnight at $50^{\circ} \mathrm{C}$, and the resulting pyridine salt was separated by filtration. The filtrate was washed with $1 \mathrm{M}$ hydrochloric acid and saturated aqueous sodium chloride, dried over magnesium sulfate, and concentrated. Purification by flash chromatography (silica, eluent; hexane-ethyl acetate $=2: 1$ ) gave $42.4 \mathrm{~g}$ $(79 \%)$ of IV as an oil.

$[\alpha]_{\mathrm{D}}^{25}=-30.7^{\circ}\left(c=0.11 \mathrm{~g} \mathrm{dl}^{-1}\right.$ in $\left.\mathrm{CHCl}_{3}\right)$.

IR (Neat): 3034, 2984, $1738(\mathrm{C}=\mathrm{O}), 1723$ $(\mathrm{C}=\mathrm{O}), 1499,1456,1408,1383,1358$, and $1273 \mathrm{~cm}^{-1}$.

${ }^{1} \mathrm{H} \mathrm{NMR}\left(\mathrm{CDCl}_{3}\right): 1.45(\mathrm{~d}, J=6.3 \mathrm{~Hz}, 6 \mathrm{H})$, $2.70(\mathrm{dd}, J=15.5 \mathrm{~Hz}, J=5.3 \mathrm{~Hz}, 2 \mathrm{H}), 2.85$ $(\mathrm{dd}, J=15.5 \mathrm{~Hz}, J=7.8 \mathrm{~Hz}, 2 \mathrm{H}), 5.10(\mathrm{~s}, 4 \mathrm{H})$, 5.55 (sextet, $J=6.3 \mathrm{~Hz}, 2 \mathrm{H}), 7.15-7.30(\mathrm{~m}$, $10 \mathrm{H})$, and $7.96(\mathrm{~s}, 4 \mathrm{H}) \mathrm{ppm}$.

MS (m/e): 517 (6), 410 (30), 324 (94), 234 (89), 176 (13), 149 (91), 121 (56), 103 (100), 91 (100), 69 (100), 42 (72), and 18 (4).

Anal. Calcd for $\mathrm{C}_{30} \mathrm{H}_{30} \mathrm{O}_{8}: \mathrm{C}, 69.49 \% ; \mathrm{H}$, $5.83 \%$. Found: C, $69.01 \%$; H, 5.69\%.

Synthesis of Ester-Containing Dicarboxylic Acid V. A suspension of IV (15.0 g, $0.0289 \mathrm{~mol})$ and $3.2 \mathrm{~g}$ of $\mathrm{Pd}-\mathrm{C}(10 \%)$ in ethanol $(150 \mathrm{ml})$ 
was stirred under hydrogen (ballon) for one day. Filtration of the mixture through celite, followed by evaporation and flash chromatography (silica, eluent, hexane-ethyl acetate = $1: 2$ then ethyl acetate alone) gave $7.8 \mathrm{~g}$ of white crystals. Recrystalization from benzene gave $6.4 \mathrm{~g}(65 \%)$ of dicarboxylic acid $\mathbf{V}$.

$\mathrm{mp} 131-132^{\circ} \mathrm{C},[\alpha]_{\mathrm{D}}^{25}=-64.9^{\circ}(c=1.07 \mathrm{~g}$ $\mathrm{dl}^{-1}$ in $\mathrm{CHCl}_{3}$ )

IR (KBr): $3000(\mathrm{OH}), 1738(\mathrm{C}=\mathrm{O}), 1715$ $(\mathrm{C}=\mathrm{O}), 1650,1505,1449,1406,1352,1315$, and $1204 \mathrm{~cm}^{-1}$.

${ }^{1} \mathrm{H}$ NMR (DMSO- $\left.d_{6}\right): 1.38(\mathrm{~d}, J=6.4 \mathrm{~Hz}$, $6 \mathrm{H}), 2.60-2.78(\mathrm{~m}, 4 \mathrm{H}), 5.35$ (sextet, $J=$ $6.3 \mathrm{~Hz}, 2 \mathrm{H}), 8.00(\mathrm{~s}, 4 \mathrm{H})$, and $11.9-12.4$ (brs, 2H) $\mathrm{ppm}$.

MS (m/e): 338 (6), 252 (74), 235 (100), 207 (13), 165 (100), 131 (100), 103 (100), 69 (100), and 41 (100).

Anal. Calcd for $\mathrm{C}_{16} \mathrm{H}_{18} \mathrm{O}_{8}: \mathrm{C}, 56.80 \% ; \mathrm{H}$, $5.36 \%$. Found: C, $56.73 \%$; H, 5.62\%.

Synthesis of Racemic Dicarboxylic Acid VIII. To an ice-cold solution of benzyl acetoacetate (I) $(18.8 \mathrm{~g}, 0.0978 \mathrm{~mol})$ in $100 \mathrm{ml}$ of benzyl alcohol was added dropwise a solution of sodium borohydride $(1.0 \mathrm{~g}, 0.0264 \mathrm{~mol})$ in $2 \mathrm{ml}$ of water over $15 \mathrm{~min}$. The mixture was stirred for $2 \mathrm{~h}$ at room temperature and $200 \mathrm{ml}$ of ether was added. The solution was washed with water, dried over magnesium sulfate, and concentrated. The ether and benzyl alcohol were subsequently removed by evaporation and by distillation $\left(60-80^{\circ} \mathrm{C} / 3\right.$ Torr $)$. The residue was purified by vacuum distillation to give $16.0 \mathrm{~g}(54.7 \%)$ of racemic benzyl 3hydroxybutanoate. The ${ }^{1} \mathrm{H}$ NMR spectrum was the same as that obtained from II.

Racemic benzyl 3-hydroxybutanoate was converted into dibenzyl ester ( $89 \%$ yield) by the same procedure as that described for the synthesis of IV. Racemic dibenzyl ester was isolated as a white crystal after recrystallization from ethanol.

$\mathrm{mp} 80-81^{\circ} \mathrm{C}$

IR (KBr): 3450, 2985, $1735(\mathrm{C}=\mathrm{O}), 1719$ $(\mathrm{C}=\mathrm{O}), 1497,1392,1300$, and $1275 \mathrm{~cm}^{-1}$.
${ }^{1} \mathrm{H}$ NMR $\left(\mathrm{CDCl}_{3}\right): 1.45(\mathrm{~d}, J=6.3 \mathrm{~Hz}, 6 \mathrm{H})$, $2.70(\mathrm{dd}, J=15.5 \mathrm{~Hz}, J=5.3 \mathrm{~Hz}, 2 \mathrm{H}), 2.85$ $(\mathrm{dd}, J=15.5 \mathrm{~Hz}, J=7.7 \mathrm{~Hz}, 2 \mathrm{H}), 5.10(\mathrm{~s}, 4 \mathrm{H})$, 5.55 (sextet, $J=6.3 \mathrm{~Hz}, 2 \mathrm{H}), 7.20-7.30(\mathrm{~m}$, $10 \mathrm{H})$, and $7.96(\mathrm{~s}, 4 \mathrm{H}) \mathrm{ppm}$.

MS (m/e): $519(23), 411(88), 384$ (5), 343 (20), 321 (100), 298 (18), 271 (20), 235 (100), 181 (57), 149 (98), 91 (100), 69 (100), 42 (72), and $18(8)$.

Anal. Calcd for $\mathrm{C}_{30} \mathrm{H}_{30} \mathrm{O}_{8}: \mathrm{C}, 69.49 \% ; \mathrm{H}$, $5.83 \%$. Found: C, $69.30 \%$; H, 5.89\%.

Racemic dibenzyl ester was hydrogenolyzed to produce racemic dicarboxylic acid VIII in $67 \%$ yield.

$\mathrm{mp} 175-177^{\circ} \mathrm{C}$

IR (KBr): $3000(\mathrm{OH}), 1720(\mathrm{C}=\mathrm{O}), 1580$, 1412,1383 , and $1270 \mathrm{~cm}^{-1}$.

${ }^{1} \mathrm{H}$ NMR (DMSO- $\left.d_{6}\right): 1.38(\mathrm{~d}, J=6.4 \mathrm{~Hz}$, $6 \mathrm{H}), 2.60-2.78(\mathrm{~m}, 4 \mathrm{H}), 5.35$ (sextet, $J=$ $6.3 \mathrm{~Hz}, 2 \mathrm{H}), 8.00(\mathrm{~s}, 4 \mathrm{H})$, and $12.1-12.4$ (brs, 2H) $\mathrm{ppm}$.

MS (m/e): 339 (6), $253(50), 235$ (96), 166 (85), 149 (100), 132 (86), 86 (99), 69 (70), 43 (70), and 28 (100).

Anal. Calcd for $\mathrm{C}_{16} \mathrm{H}_{18} \mathrm{O}_{8}: \mathrm{C}, 56.80 \% ; \mathrm{H}$, $5.36 \%$. Found: C, $56.63 \%$; H, 5.43\%.

\section{Polymerization}

A typical example of the polycondensation is described below.

Polyester-amide VIIc. A mixture of dicarboxylic acid V $(0.846 \mathrm{~g}, 2.5 \mathrm{mmol}), 4,4^{\prime}$-oxydianiline $(0.501 \mathrm{~g}, 2.5 \mathrm{mmol})$, triphenyl phosphite $(1.60 \mathrm{~g}, 5.2 \mathrm{mmol})$, pyridine $(1.25 \mathrm{ml})$, and calcium chloride $(0.25 \mathrm{~g})$ in $5 \mathrm{ml}$ of NMP was slowly stirred at $100^{\circ} \mathrm{C}$ under nitrogen. As the polycondensation proceeded, the solution became turbid and viscous. After having stirred for $3 \mathrm{~h}$, the reaction mixture was poured into $180 \mathrm{ml}$ of methanol. The precipitated polymer was isolated, then washed thoroughly with hot methanol. Drying under vacuum gave $1.07 \mathrm{~g}$ $(85 \%)$ of polyester-amide VIIc with an inherent viscosity of $0.44 \mathrm{dl} \mathrm{g}^{-1}$ measured at a concentration of $0.5 \mathrm{~g} \mathrm{dl}^{-1}$ in DMAc at $30^{\circ} \mathrm{C}$.

IR (Film): 3294 (NH), 3138, 3070, 2984, 
2983, 1721 (ester $\mathrm{C}=\mathrm{O}$ ), 1663 (amide $\mathrm{C}=\mathrm{O}$ ), $1638,1547,1502,1408$, and $1272 \mathrm{~cm}^{-1}$.

${ }^{1} \mathrm{H}$ NMR (DMSO- $\left.d_{6}\right): 1.40(\mathrm{~d}, J=6.3 \mathrm{~Hz}$, $6 \mathrm{H}), 2.68(\mathrm{dd}, J=14.9 \mathrm{~Hz}, J=9.26 \mathrm{~Hz}, 2 \mathrm{H})$, $2.78(\mathrm{dd}, J=14.7 \mathrm{~Hz}, J=7.5 \mathrm{~Hz}, 2 \mathrm{H}), 5.45$ (sextet, $J=6.0 \mathrm{~Hz}, 2 \mathrm{H}), 6.90(\mathrm{~d}, J=9.0 \mathrm{~Hz}$, $4 \mathrm{H}), 7.52(\mathrm{~d}, J=9.0 \mathrm{~Hz}, 4 \mathrm{H}), 8.00(\mathrm{~s}, 4 \mathrm{H})$, and 9.95 (s, 2H) ppm.

Anal. Calcd for $\mathrm{C}_{28} \mathrm{H}_{26} \mathrm{~N}_{2} \mathrm{O}_{7}: \mathrm{C}, 66.92 \%$; H, 5.21\%; N, 5.57\%. Found: C, 67.33\%; H, $5.22 \% ; \mathrm{N}, 5.51 . \%$.

\section{REFERENCES}

1. M. S. Toy, J. Polym. Sci., 5, 2481 (1967); Y. Minoura, S. Urayama, and Y. Noda, J. Polym. Sci.,
5, 2441 (1967); H. Yamaguchi, H. Ueno, and Y. Minoura, J. Polym. Sci., 9, 887 (1971); H. Yamaguchi and Y. Minoura, J. Polym. Sci., 11, 763 (1973); Y. Iwakura, K. Hayashi, and K. Inagaki, Makromol. Chem., 110, 84 (1968); V. Jarm and Z. Jnovic., J. Polym. Sci., Polym. Chem. Ed., 16, 3007 (1978).

2. N. Koide and K. Taki, Rep. Prog. Polym. Phys. Jpn., 32, 201 (1989); N. Koide, K. Taki, and K. Ninomiya, Polym. Prepr. Jpn., 39, 2361 (1990).

3. R. Noyori, T. Ohkuma, M. Kitamura, H. Takaya, N. Sayo, H. Kumobayashi, and S. Akutagawa, $J$. Am. Chem. Soc., 109, 5856 (1987).

4. M. Kunioka and Y. Doi, Macromolecules, 23, 1933 (1990).

5. S. Murahashi, Gosei Koubunshi V, S. Murahashi, M. Imoto, and H Tani, Ed., Asakura, Tokyo, 1971, p 200.

6. Z. Jedlinski, M. Kowalczuk, W. Glowkowski, and J. Grobleny, Macromolecule, 24, 349 (1991). 